\title{
Injectable Dexamethasone Administration Enhances Cortical GABAergic Neuronal Differentiation in a Novel Model of Postnatal Steroid Therapy in Mice
}

\author{
OLIVIER BAUD, CATHERINE VERNEY, PHILIPPE EVRARD, AND PIERRE GRESSENS \\ Laboratoire de Neurobiologie du Développement [O.B., C.V., P.E., P.G.], INSERM E9935, Paris, France; \\ and Service de Néonatologie [O.B.] and Service de Neurologie [P.E., P.G.], Hôpital Robert Debré, \\ F-75019 Paris, France
}

\begin{tabular}{|c|c|}
\hline \multicolumn{2}{|c|}{ ABSTRACT } \\
\hline $\begin{array}{l}\text { Injectable dexamethasone (DXM) is widely used during the } \\
\text { postnatal period in premature infants. However, this treatment } \\
\text { has been associated with an increased incidence of neuromotor } \\
\text { disorders. Few studies have directly addressed the impact of } \\
\text { DXM therapy on neuronal differentiation. We used a murine } \\
\text { model of postnatal steroid therapy in which mouse pups aged } 3 \\
\text { and } 4 \text { postnatal days (P) received intraperitoneal injections of } 1 \\
\mathrm{mg} \cdot \mathrm{kg}^{-1} \cdot 12 \mathrm{~h}^{-1} \text { of an injectable preparation that contained } \\
\text { DXM and sulfites (DXM), pure DXM, or sulfites. The animals } \\
\text { were weighed before they were killed on P5, P10, or P21, and } \\
\text { their brains were investigated by immunohistochemistry with } \\
\text { markers for neuronal differentiation. DXM administration was } \\
\text { associated with a } 20-30 \% \text { reduction in body and brain weight } \\
\text { gains and in cortical thickness on P5 and P10. } \gamma \text {-Amino-butyric } \\
\text { acid }+(\mathrm{GABA}+) \text { interneuron density was significantly increased } \\
\text { ( }+50 \%) \text { in the cerebral cortex of the animals given injectable } \\
\text { DXM on P5 to P } 21 \text { compared with controls ( } p<0.01) \text {. In } \\
\text { parallel, the density of cortical neurons expressing two interneu- } \\
\text { ron markers (calbindin } 28 \text {-kD and calretinin) increased signifi- }\end{array}$ & $\begin{array}{l}\text { cantly. These alterations occurred with injectable DXM but not } \\
\text { with pure DXM or sulfites alone. In contrast, none of the study } \\
\text { treatments modified the expression of other markers for neuronal } \\
\text { transmission or axon myelination. In the animals that were given } \\
\text { injectable DXM, cleaved caspase } 3 \text { antibody showed increased } \\
\text { neuronal cell death, but calbindin antibody did not. In conclu- } \\
\text { sion, in a murine model of postnatal steroid therapy, injectable } \\
\text { DXM induced a selective increase in GABAergic neurons in the } \\
\text { cerebral cortex. (Pediatr Res 57: 149-156, 2005) } \\
\text { CaBP, calbindin 28-kD protein } \\
\text { CalR, calretinin } \\
\text { DXM, dexamethasone } \\
\text { GABA, } \gamma \text {-amino-butyric acid } \\
\text { GAD, glutamic acid decarboxylase } \\
\text { IR, immunoreactive } \\
\text { P, postnatal day } \\
\text { PAR1, parietal } 1 \text { area }\end{array}$ \\
\hline
\end{tabular}

Despite substantial improvements in neonatal intensive care and pregnancy management over the last two decades, prematurity remains a crucial public health issue as a major source of death and permanent disability (1). These outcomes are related mainly to abnormalities of the CNS and lungs. To either prevent severe chronic lung disease or treat hemodynamic failure, early postnatal dexamethasone (DXM) therapy is often administered parenterally (injectable DXM) to extremely low birth weight infants. In the 1980s and 1990s, several controlled

Received August 20, 2003; accepted June 23,2004.

Correspondence: Olivier Baud, M.D., Ph.D., INSERM E9935, Hôpital Robert Debré, 48 bd Sérurier 75019 Paris, France; e-mail: o.baud@rdb.ap-hop-paris.fr

This study was sponsored by INSERM, Fondation Grace de Monaco, and the Association des Juniors en Pédiatrie.

DOI: 10.1203/01.PDR.0000148069.03855.C4 studies found shorter times on oxygen and mechanical ventilation in premature infants who were given postnatal i.v. DXM therapy, which consequently gained widespread acceptance (2-5). However, controversy about the extensive use of postnatal steroid therapy has recently been generated by reports of adverse effects, mainly affecting the CNS. An increased risk for cerebral palsy is among the main adverse effects of injectable DXM (6-11). Three-dimensional magnetic resonance imaging at term suggests that steroid-induced impairment of brain growth may primarily affect the cortical gray matter by decreasing both the brain surface area and the whole cortex convolution index, which is used to measure cortical surface complexity at term $(12,13)$. A reduction in spontaneous motility was noted in neonates who were given injectable DXM, together with changes in the speed and the amplitude of general 
movements, all of these abnormalities being related to brain lesion severity and to the subsequent development of cerebral palsy (14). In vitro, we previously found that the sulfites used as preservatives in injectable DXM preparations exerted toxic effects on neurons, which might in theory dampen any protective effect of glucocorticoids on the CNS (15). In vivo animal models are under investigation as tools for elucidating the adverse neurologic effects of glucocorticoids that are given perinatally (16-20). However, the impact of glucocorticoids on neuronal differentiation, most notably in the cerebral cortex, has never been reported.

The mammalian neocortex contains two major classes of neurons, projection and local circuit neurons. Inhibitory local circuit neurons that contain $\gamma$-amino-butyric acid (GABA) represent $\sim 15 \%$ of the overall neuronal population in rodents (21). The other neurons are projection neurons that use excitatory amino acids such as glutamate. Specific layers and areas of the cerebral cortex receive monoaminergic axonal afferents from neuronal cell bodies located in various brainstem nuclei (22-24).

The present study was designed to explore a mouse model of prolonged neonatal DXM treatment. The specific goal of this new model is to closely mimic glucocorticoid protocols used in premature infants who are admitted to neonatal intensive care units and aged 26 to 32 postconceptional weeks, which matches postnatal days (P) 3 to 5 in mice, when neuronal proliferation and migration in the cerebral neocortex is complete (25). The objective of the study was to determine whether DXM with or without sulfites affects neuronal differentiation to a specific neurotransmitter function in the developing cerebral cortex.

\section{METHODS}

Animals and experimental design. Male and female Swiss mouse pups (Iffa Credo, L'Abresle, France) were housed in our animal unit and maintained according to the guidelines issued by the Institut National de la Santé et de la Recherche Médicale. All experimental protocols were approved by our ethics review committee. All animals were kept under the same temperature $\left(25^{\circ} \mathrm{C}\right)$ and photoperiodicity (12:12-h light-dark cycle) conditions and were given free access to food and water.
In this mouse model, newborn pups are exposed to DXM at an age that matches the neurodevelopmental stage of human infants who are given DXM in neonatal intensive care units. The pups were divided into four groups on postnatal day (P) 3. From P3 to P5, they received five i.p. injections at 12-h intervals of the following drugs, in a volume of $5 \mu \mathrm{L}$ : PBS (control group for both injectable DXM and sulfites) or DMSO (control group for pure DXM); injectable DXM (Merck, Paris, France), $1 \mathrm{mg} / \mathrm{kg}$ diluted in PBS (DXM group); pure DXM (Sigma Chemical Co., St. Louis, MO), $1 \mathrm{mg} / \mathrm{kg}$ diluted in DMSO (pure DXM group); and sodium metabisulfite (Sigma Chemical Co.), $1 \mathrm{mg} / \mathrm{kg}$ diluted in PBS (sulfite group). In each litter, pups were assigned to the study drug or control groups.

Weight and mortality were recorded before the injections on P3 then on P5, P10, and P21. Brain weights were obtained during necropsy on P10 after removing the cerebellum, in animals that were different from those used for immunocytochemistry procedures.

Plasma DXM concentrations measurement. Blood samples were drawn from decapitated P5 pups at several time points $(0.5,1,3$, and $6 \mathrm{~h})$ after intraperitoneal injection of either injectable DXM diluted in PBS or pure DXM diluted in DMSO. After centrifugation, plasma was collected and kept at $-80^{\circ} \mathrm{C}$. DXM was extracted in dichloromethane, and its concentration in both treated groups was measured by HPLC. DXM concentrations were calculated after UV detection and expressed in $\mathrm{ng} / \mathrm{mL}$.

Histologic procedures. We studied at least five animals on P5, P10, and P21 in the control and injectable DMX groups. Treated groups and their respective control groups were compared on P5, P10, and P21 for injectable DXM and on P10 for pure DXM and sulfites. For standard histologic procedures, animals were decapitated at the same time points and their brains were removed immediately and fixed in $4 \%$ formalin for $5 \mathrm{~d}$ at room temperature. After paraffin embedding, serial $10-\mu \mathrm{m}$ coronal sections were cut throughout each brain. These sections were stained with cresyl violet used for cortical plate thickness and cellular density measurement by an investigator who was unaware of group assignment. For avoiding bias related to regional variations, the same anatomic level was examined in each group. Images of the parietal cortex area (PAR1) (26) were digitized using a CCD camera (Apogee Instrument Inc., Boston, MA) to allow accurate measurements.

Immunocytochemistry. Pups under deep anesthesia received a transcardiac infusion of phosphate buffer ( $\mathrm{pH} 7.4,0.12 \mathrm{M}$ ) that contained $4 \%$ paraformaldehyde. The dissected brains were postfixed in the same fixative for $4 \mathrm{~h}$ at $4{ }^{\circ} \mathrm{C}$. After rinses in $10 \%$ sucrose in phosphate buffer, the cryoprotected brains were frozen in liquid nitrogen-cooled isopentane at $-50^{\circ} \mathrm{C}$ and stored at $-80^{\circ} \mathrm{C}$ until cryostat cutting. The brains were cut into serial $10-\mu \mathrm{m}$-thick cryostat sections, which were processed for immunocytochemistry. The primary antibodies were directed against various antigens specific for cell types (microglia, astrocytes, and neurons) or neuronal differentiation (Table 1). The sections were rinsed in PBS/0.25\% Triton X-100/0.2\% gelatin (PBS-TX-gel) and incubated overnight at room temperature with appropriately diluted primary antibody in PBS-TX-gel with $0.02 \%$ sodium azide. The primary antibodies

Table 1. Primary antibodies used in the study

\begin{tabular}{|c|c|c|c|}
\hline Name & Manufacturer & Type & Dilution \\
\hline GABA & Sigma, St. Louis, MO & Rabbit polyclonal & $1: 4000$ \\
\hline Calbindin $28-\mathrm{kD}$ protein & Swant, Bellinzona, Switzerland & Rabbit polyclonal & $1: 5000$ \\
\hline Calbindin $28-\mathrm{kD}$ protein & Swant & Mouse monoclonal & $1: 1000$ \\
\hline Calretinin & Swant & Rabbit polyclonal & $1: 5000$ \\
\hline NMDA-R2 & Chemicon, Temecula, CA & Rabbit polyclonal & $1: 100$ \\
\hline Cam kinase II & Cell Signaling, Beverly, MA & Rabbit polyclonal & $1: 500$ \\
\hline $5-\mathrm{HT}$ & Immunotech, Luminy, France & Rabbit polyclonal & $1: 10000$ \\
\hline $\mathrm{TH}$ & Gift from Dr. Vigny (41) & Rabbit polyclonal & $1: 500$ \\
\hline NeuN & Chemicon & Mouse monoclonal & $1: 500$ \\
\hline MAP2 & Chemicon & Mouse monoclonal & $1: 500$ \\
\hline GFAP & Dako, Glostrup, Denmark & Rabbit polyclonal & $1: 500$ \\
\hline $\mathrm{S} 100 \beta$ protein & Swant & Rabbit polyclonal & $1: 2000$ \\
\hline Griffonea Simplicifolia I Isolectin B4 & Vector, Burlingame, CA & Biotin conjugated & $1: 500$ \\
\hline Cleaved caspase 3 & Cell Signaling & Rabbit polyclonal & $1: 200$ \\
\hline
\end{tabular}

NMDA-R2, N-methyl-D-aspartate receptor 2; cam kinase II, calmodulin-dependent protein kinase II; TH, tyrosine hydroxylase; MAP2, microtubule-associated protein 2; GFAP, glial fibrillary acidic protein. 
were visualized after incubations with the appropriate species-specific biotinylated secondary antibody (Table 1) and the streptavidin-biotin-peroxidase complex.

For Griffonea Simplicifolia I isolectin B4 (Vector, Burlingame, CA) labeling, the streptavidin-biotin-peroxidase method was used without secondary antibody. The sections were counterstained with neutral red (1\%), dehydrated, and mounted.

For immunofluorescent double staining, sections were incubated overnight with a mixture of two primary antibodies (mouse anti-CaBP and rabbit anti-cleaved caspase 3) at a concentration of twice the dilutions shown in Table 1. The sections were rinsed and incubated with a biotinylated anti-mouse secondary antibody (Vector). The second incubation with streptavidin-biotincyanine 3 (1:500; Sigma Chemical Co.) labeling in red was combined with application of FITC-labeled anti-rabbit antibody (1:100, Sigma Chemical Co.) labeling in green. Immunocytochemical controls in which the primary antibody was omitted were performed for the different immunocytochemical methods to check that there was no cross-reactivity of the secondary antibodies.

Microscopy. Bright field illumination was used to examine sections from PAR1 (26) and the white matter in the cingulum at the same frontal level [Figs. 30-37 and 15-20 in the Paxinos atlas (27), respectively]. A CCD camera was used to digitize the region of interest to improve the accuracy of the labeled cell counts. In each group, three to five animals at each developmental stage were studied; at least three nonadjacent fields from either right or left hemisphere in a section included within a square-grid reticule were examined. Sections were observed at either $\times 40$ or $\times 20$ magnification $\left(0.065 \mathrm{~mm}^{2}\right.$ and $0.25 \mathrm{~mm}^{2}$, respectively) to get the most reliable cell counts according to the cellular morphology of each marker considered. The observer who examined the sections was not aware of the developmental stage or group.

Statistical analysis. Results were expressed as means \pm SEM. Statistical analysis of the histologic data were performed using one-way ANOVA with a Dunnett comparison posttest, two-way ANOVA with a Bonferroni posttest, or a $t$ test, as appropriate (GraphPad Prism version 3.03 for Windows; GraphPad Software, San Diego, CA).

\section{RESULTS}

Phenotype of postnatal DXM-treated mouse pups. Mortality rates were $0 \%$ in the saline buffer and $10 \%$ in the DMSO control groups, $17 \%$ in the injectable DXM group, $45 \%$ in the pure DXM group, and 10\% in the sulfites group. Most deaths were related to repetitive i.p. injections combined with the potential local toxicity of glucocorticoids on the intestinal tract; thus, most of the animals that died before they were killed displayed clinical evidence of peritonitis. The higher mortality rate in the pure DXM group may be ascribable to the combined effects of the glucocorticoid and the corrosive vehicle (DMSO). We further measured DXM concentrations in plasma at several time points after i.p. injection. As expected, using HPLC measurement, we found similar levels between the two regimens used in this study (Fig. 1).

Before treatment, body weight was similar (controls $2.16 \pm$ $0.12 \mathrm{~g}, n=12$; DXM $2.09 \pm 0.06 \mathrm{~g}, n=9$; pure DXM $2.2 \pm$ $0.05 \mathrm{~g}, n=9$; and sulfites, $2.3 \pm 0.13 \mathrm{~g}, n=8$; Fig. $2 A$ ). In contrast, injectable DXM and pure DXM were associated with significant reductions in body weight compared with the respective control groups and with the sulfite-treated group on P5 (controls $3.23 \pm 0.13 \mathrm{~g}$; injectable DXM $2.39 \pm 0.13 \mathrm{~g}$; pure DXM $2.24 \pm 0.09 \mathrm{~g}$; sulfites $3.3 \pm 0.8 \mathrm{~g} ; p<0.01$ ) and on P10 (controls $5.77 \pm 0.15 \mathrm{~g}$; injectable DXM $4.47 \pm 0.28 \mathrm{~g}$; pure DXM $4.11 \pm 0.3 \mathrm{~g}$; and sulfites $6.48 \pm 0.35 \mathrm{~g} ; p<0.01$; Fig. $2 A)$. On P21, DXM-treated pups had recovered a body weight similar to that measured in the controls (controls $13.61 \pm$ $0.31 \mathrm{~g}$; DXM $12.91 \pm 0.17 \mathrm{~g}$ ). This poor weight gain during and just after glucocorticoid therapy was associated with a

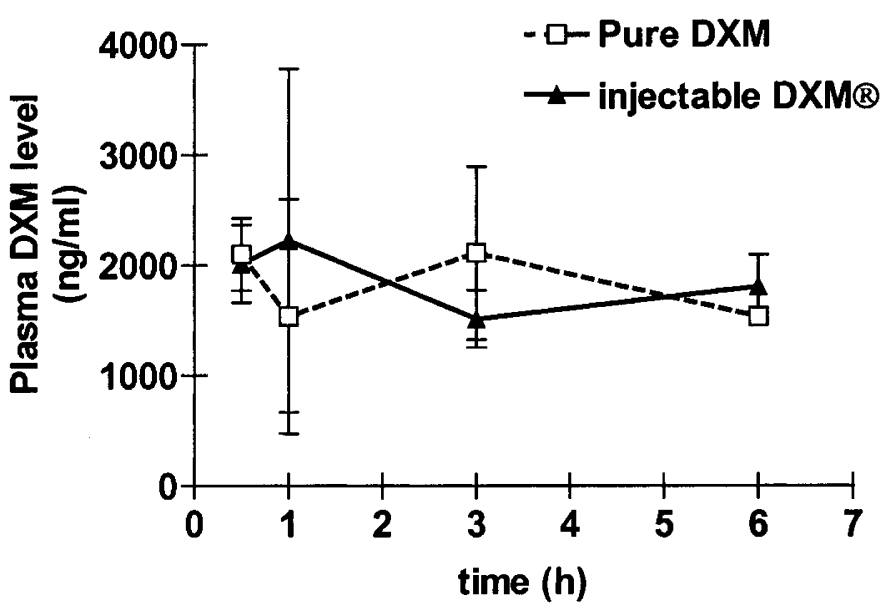

Figure 1. Plasma DXM concentrations using pure DXM or injectable DXM preparations. No difference was observed in DXM concentrations obtained by HPLC analysis, from 0.5 to $6 \mathrm{~h}$ hours after i.p. administration of either pure DXM or injectable DXM (results are expressed as mean $\pm \mathrm{SD}$ ).
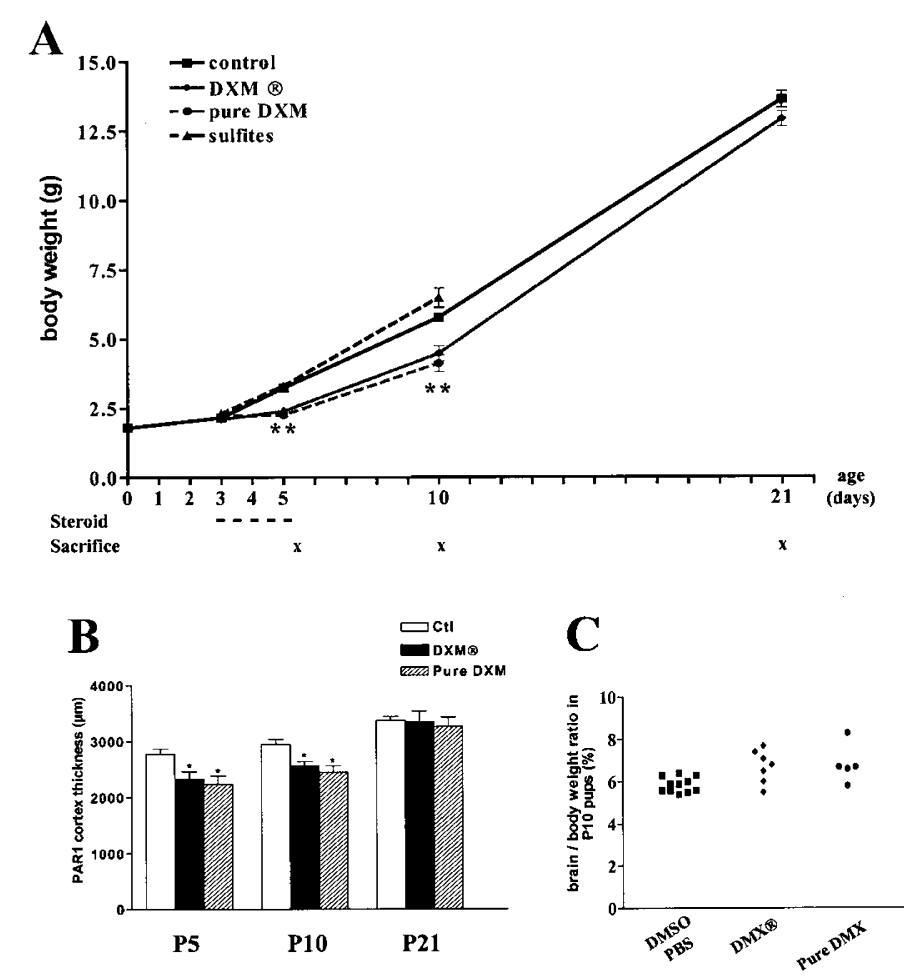

Figure 2. Phenotype associated with postnatal DXM therapy in mouse pups. (A) Body weight gains in controls, DXM-treated pups, and sulfite-treated pups during the first 3 wk of life $(* * p<0.01$ using two-way ANOVA with the Bonferroni multiple comparisons posttest). (B) Cortical thickness of the brain (PAR1 area) in untreated and DXM-treated pups $\left({ }^{*} p<0.05\right.$ using two-way ANOVA with the Bonferroni multiple comparisons posttest). (C) Brain/body ratio in the DXM groups and controls.

significant decrease in PAR1 cortical plate thickness compared with the controls on P5 and P10 $(p<0.05)$ with both injectable DXM and pure DXM (Fig. 2B). Brain weight on P10 showed a similar pattern, so the body weight/brain weight ratio was comparable in the two groups (Fig. 2C). Again, on P21, no difference was found between the groups.

To analyze a potential direct role for injectable DXM on the observed cerebral alterations, we investigated the anti- 
inflammatory effects of DXM on the white matter. Griffonea Simplicifolia I isolectin B4 immunocytochemistry established that injectable DXM was associated on P5 with a dramatic but transient 4-fold decrease in the number of activated microglial cells detected in the white matter underlying the cingular cortex (Fig. 3).

Effect of injectable DXM on GABAergic cortical interneurons. Exposure to injectable DXM induced dramatic alterations in GABAergic neuronal density in the cortical plate of mouse pups. We used three markers for GABAergic neurons in the cortical plate: GABA and two calcium-binding proteins found in different subpopulations of interneurons, namely, calbindin $28-\mathrm{kD}$ protein $(\mathrm{CaBP})$ and calretinin (CalR) (28).

After injectable DXM treatment, the density of GABA immunoreactive (IR) neurons was significantly increased throughout the cerebral cortex from P5 to P21 (Fig. 4). This difference was particularly marked in the cingular cortex and anterior neocortex. However, the decrease in GABA+ neuron density normally observed in the normal developing rodent brain was not altered after injectable DXM treatment.

Injectable DXM was also associated with an increase in $\mathrm{CaBP}+$ neuron density in layers II-III and in layer V of PAR1 (Fig. 5A and $B$ ). This difference became larger as development proceeded; thus, no obvious change was found on $\mathrm{P} 5$, whereas on P10, there was a $36 \%$ increase and on P21 a $>300 \%$ increase ( $p<0.05$ and $p<0.001$, respectively; Fig. 5C). In addition to this quantitative increase, the intensity of $\mathrm{CaBP}+$ neuron labeling was enhanced in the cortical plate. Finally, the number of CalR-IR neurons detected in PAR1 layer V was increased 1.5- to 2-fold in the treated pups on P10 and P21, respectively $(p<0.01, p<0.05$; Fig. 6 ). These effects were found to be dose dependent (Fig. 7). The location and the time of appearance of these GABAergic neurons in the cortical plate were similar in the treated and control groups.

Effect of pure DXM and of sulfites alone on cortical interneurons. Because sulfites were previously reported to be involved in neuronal toxic effect in culture (15), we next asked whether pure DXM or sulfites alone might reproduce the effects on neuronal maturation observed with injectable DXM. To test this hypothesis, we compared pure DXM and sulfites with their respective controls on P10 pups (P10 was selected as this is the time point when injectable DXM induced the greatest changes in GABAergic markers). In contrast to inject- able DXM, neither pure DMX nor sulfite treatment was associated with statistically significant differences in cell density or labeling intensity of GABA-IR or CaBP-IR neurons in the same PAR1 area, compared with the control groups, on P10 (Fig. 8). Examination of other cortical plate regions led to similar conclusions. Pure DXM was associated with a nonsignificant decrease in CalR-IR neuron density at the same time point, compared with DMSO-injected controls (Fig. 8C).

Effect of injectable DXM on other transmitters and on neuronal and glial markers. We used markers for other neurotransmitters for qualitative analysis (distribution and intensity of labeling, organization, and density of labeled structures) of sections through the cortical plate or other brain structures according to the location of each marker during the first three postnatal weeks. N-methyl-D-aspartate receptor 2 was expressed in the cortical plate (faint staining in layer V), hippocampus, and basal ganglia (29), and strong calmodulindependent protein kinase II labeling was seen in the granular layer of the hippocampus (30). These two glutamatergic synapse markers showed no significant differences between control and DXM-treated pups on P10. Similarly, 5-HT-labeled axons and tyrosine hydroxylase-positive axons and terminals (both densely expressed in the basal ganglia) showed no differences across treatments. Similar results were obtained with two other typical neuronal markers, NeuN for neuronal nuclei and microtubule-associated protein 2 for neuronal cell bodies and processes.

In contrast to neuronal maturation, neither astrocyte differentiation nor myelination was altered by postnatal injectable DXM treatment. Astrocyte maturation was assessed by both glial fibrillary acidic protein and $\mathrm{S} 100-\beta$ protein expression in the white matter. Cell counts in the cingular white matter were similar between treated and untreated animals (data not shown). Axon myelination assessed using myelin basic protein was not delayed on P10 by injectable DXM pretreatment in this mouse model.

Effect of injectable DXM on neuronal cell death. To further investigate the mechanism underlying the increased density of GABAergic neurons after injectable DXM administration, we investigated cell death in the cortical plate on P5, just after the end of the treatment. Several findings supported neuronal loss in the cortical plate in the pups that were given injectable DXM. Thus, whereas the transient cortical thickness decrease
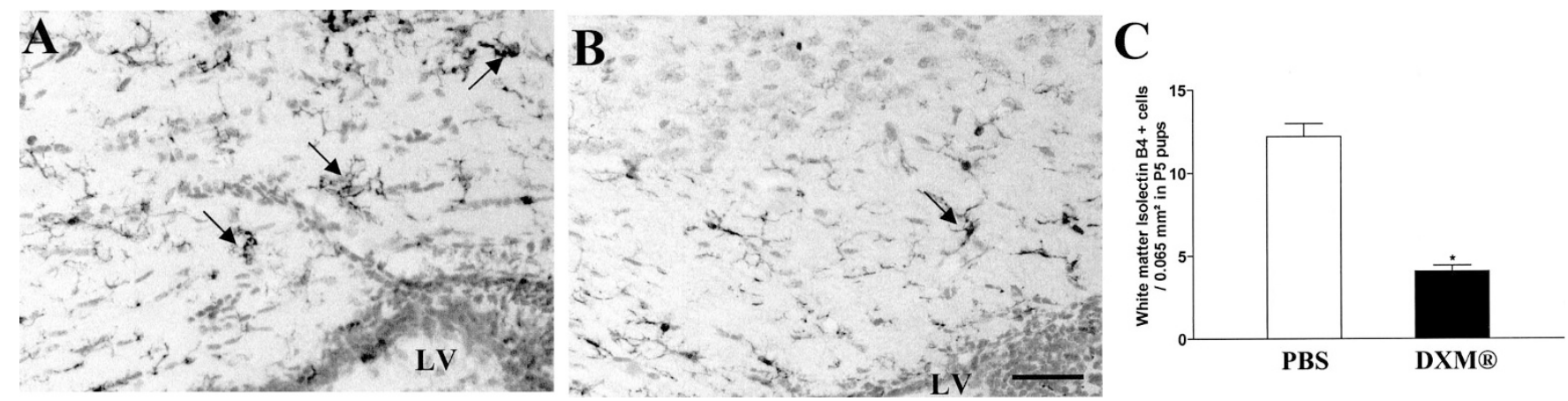

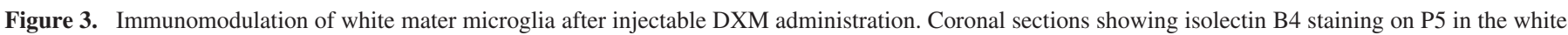

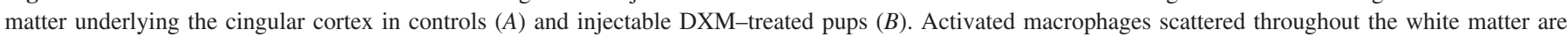

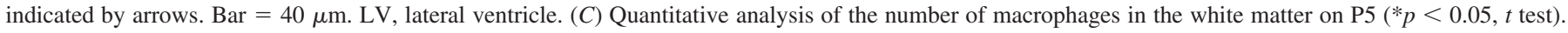



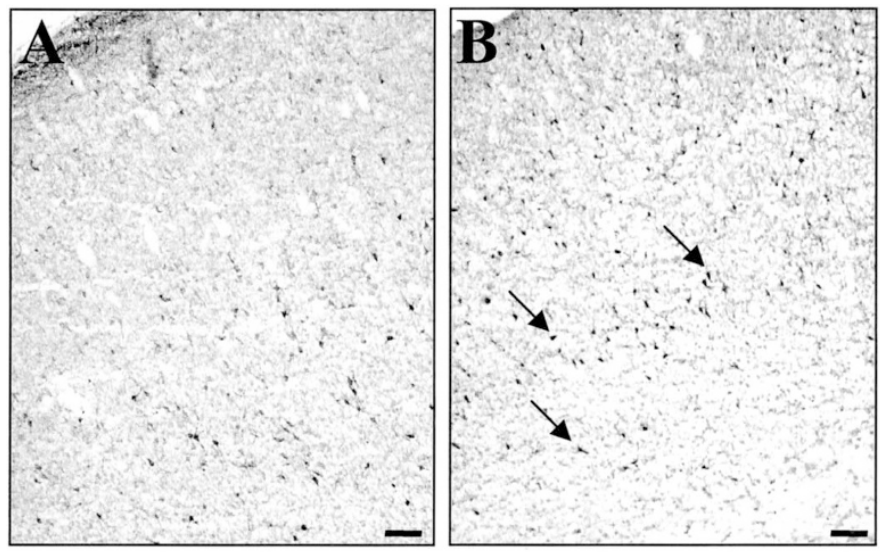

C

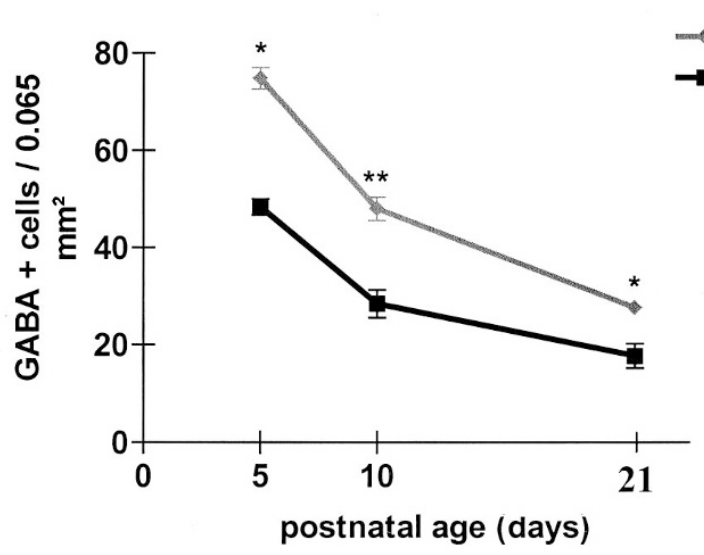

Figure 4. Injectable DXM increased GABA + neurons in the cortical plate. $(A$ and $B$ ) Representative coronal sections from injectable DXM-treated pups or controls (PBS) on P10. Immunolabeling for GABA (the arrows indicate immunoreactive neurons). Bar $=40 \mu \mathrm{m}$. (C) Quantitative analysis of the number of GABA+ neurons in the cingular cortex after injectable DXM or PBS given intraperitoneally $(* * p<0.01, * p<0.05$ in two-way ANOVA with the Bonferroni multiple comparisons posttest).

observed after injectable DXM resolved spontaneously within 2 wk (Fig. 9A), neuronal density decreased gradually in the cerebral cortex, compared with the controls (Fig. 9B). Thus, a significant reduction in neuronal density in PAR1 was detected on P21 in the treated animals $\left(58.7 \pm 8.5\right.$ neurons $/ 0.065 \mathrm{~mm}^{2}$ in the injectable DXM group versus $66.7 \pm 7.2$ neurons/0.065 $\mathrm{mm}^{2}$ in the control group; $p<0.05$ ). In addition, injectable DXM was associated with a statistically significant increase in cleaved caspase 3-IR neurons throughout the cortical plate on P5 (Fig. 9C-E). This difference was particularly marked in layer II in the medial part of the cerebral cortex and in layers II-V in the lateral cortex. To identify the neuron subpopulation undergoing increased cell death, we performed double labeling using both rabbit anticleaved caspase 3 and mouse monoclonal anti-CaBP antibodies. Most cleaved caspase $3+$ cells exhibited the morphologic features of neurons, and almost none were $\mathrm{CaBP}+$, suggesting that injectable DXM was associated with cell death of one or more other neuronal subpopulations (Fig. 9F).
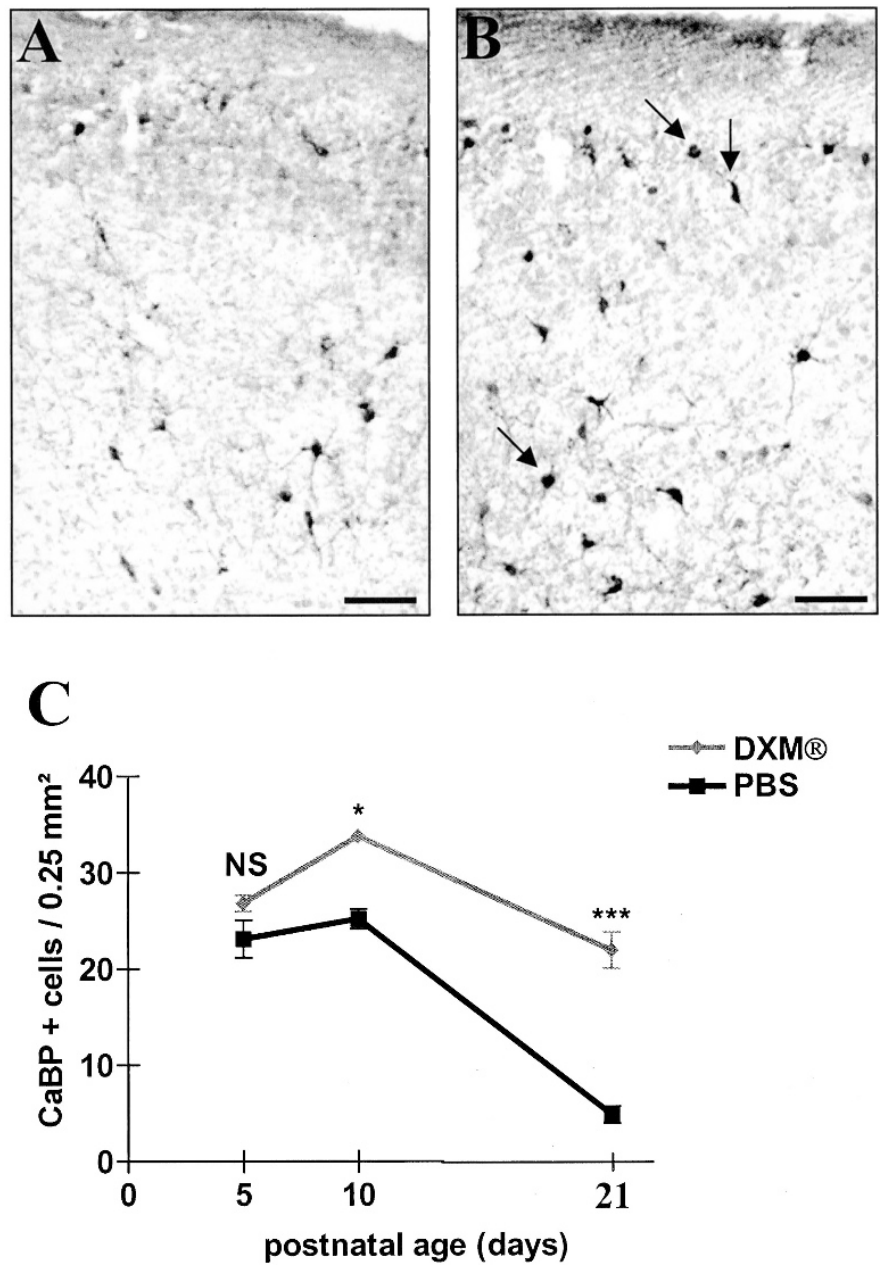

Figure 5. Injectable DXM increased calbindin + neurons in the cortical plate. $(A$ and $B$ ) Representative coronal sections from injectable DXM-treated pups or controls (PBS) on P10. Immunolabeling for CaBP (the arrows indicate immunoreactive neurons in layers II, III, and V, with various morphologies). Bar $=40 \mu \mathrm{m}$. (C) Quantitative analysis of the number of CaBP neurons in the parietal cortex (PAR1) after injectable DXM or PBS given intraperitoneally $(* * * p<0.001, * p<0.05$ in two-way ANOVA with the Bonferroni multiple comparisons posttest).

\section{DISCUSSION}

The present study describes a new mouse model of postnatal glucocorticoid therapy and provides strong evidence for a direct impact of injectable DXM on neuronal maturation. In this model, the influence of DXM treatment on the phenotype was confirmed by several findings: 1 ) a transient impairment in body and brain growth during the first week after glucocorticoid administration, 2) a decrease in microglial activation detected in the normal white matter during the first week of life, and 3) a reduction in cortical thickness during the same period. Spontaneous recovery of normal cortical thickness may be due to an increased neuritogenesis or local inflation in water content after the end of the glucocorticoid course. Thus, this model replicates several of the adverse effects of postnatal corticosteroid therapy in preterm newborns; other replicated effects were intestinal perforation and changes in skin appearance. Although the doses of glucocorticoids or sulfites used in this study represented $\sim 4-10$ times the dose generally used in 

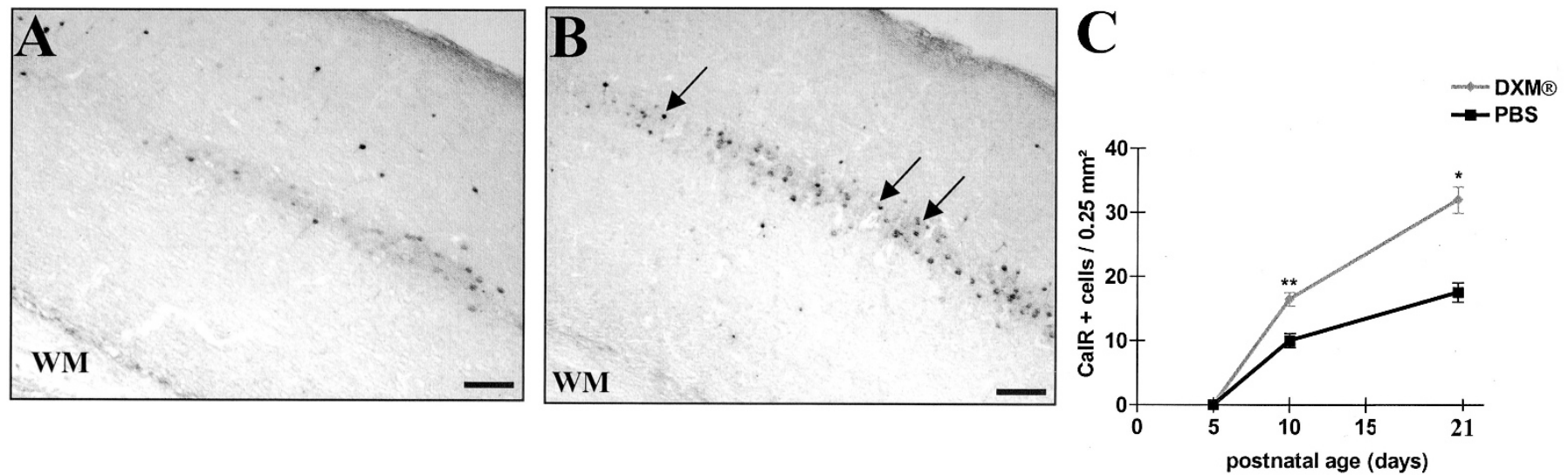

Figure 6. Injectable DXM increased CalR + neurons in the cortical plate. ( $A$ and $B$ ) Representative coronal sections from injectable DXM-treated pups or controls (PBS) on P10. Immunolabeling for CalR (the arrows indicate immunoreactive neurons). Bar $=40 \mu \mathrm{m}$. WM, white matter. (C) Quantitative analysis of the number of CalR neurons in the parietal cortex (PAR1) following injectable DXM® or PBS given intraperitoneally $(* * p<0.01, * p<0.05$ in two-way ANOVA with the Bonferroni multiple comparisons posttest).

preterm newborns, the observed phenotype suggests that both the systemic and the cerebral effects of these regimens in neonatal mice were similar to those observed in humans. Moreover, glucocorticoid metabolic rates and pharmacodynamics may differ between mouse pups and human newborns; consequently, comparisons of dosages should be viewed with caution.

Regarding brain development, although caution is needed when extrapolating from animal models to the clinical setting, only moderate differences in the general sequence of brain growth exist between rodents and humans (25). The brain growth rate, periventricular germinal matrix composition, and neurochemical expression and synapse formation in the rat brain on P6 are roughly similar to the developmental stage of the human brain at 38-40 wk of postconceptional age $(25,31,32)$. The rat pup brain at birth $(\mathrm{P} 0)$ probably corresponds to the human brain at $22-24$ wk of gestation (33). As mouse brain development is delayed $1-2 \mathrm{~d}$ compared with rats, P3-P5 mouse pups probably mimic the developmental stage of the human brain at 26-34 wk of gestation.

Other animal models have been used to study the neurologic effects of perinatal glucocorticoid use (16-20). The animals were exposed to DXM at an age corresponding to the neurologic development at birth in preterm infants. Delays in gross neurologic development occurred, as well as subsequent modifications in activity. These alterations may correspond to the increased risk for learning impairment and maladaptive responses to the environment in children with prematurityrelated brain damage.

Here, we report the first evidence that neonatal administration of injectable DXM strongly affects neuronal GABAergic differentiation in the mouse cerebral cortex. As mentioned above, two main categories of neurons are involved in neocortical organization: projection (pyramidal) neurons that contain the excitatory neurotransmitter glutamate and local circuit inhibitory neurons (nonpyramidal) that contain GABA. As a result of its excitatory effect during development, GABA is a potent trophic factor early in life and influences parameters such as neuronal survival, growth cone guidance, and neurite

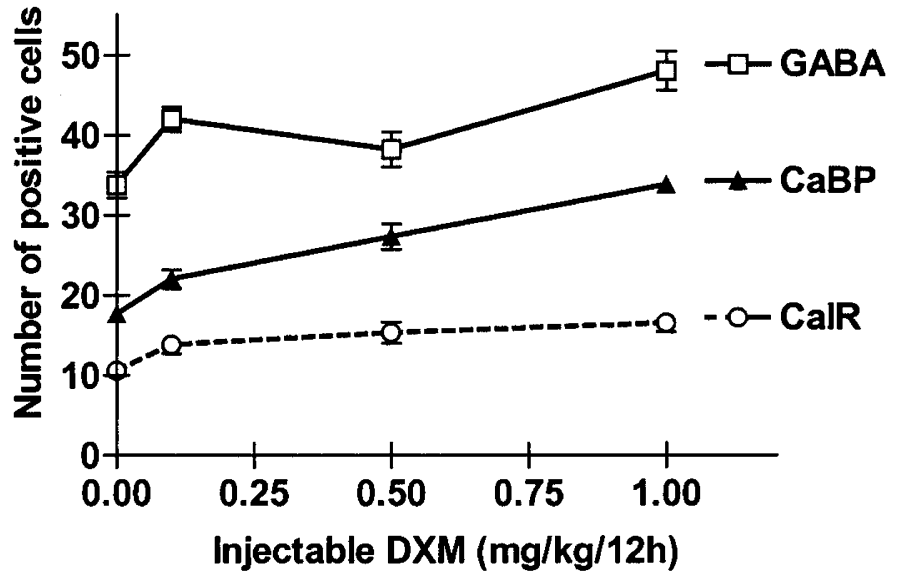

Figure 7. Injectable DXM administration induced a dose-dependent increase of the number of GABAergic neurons in the cortical plate. Quantitative analysis of the number of $\mathrm{GABA}+, \mathrm{CaBP}+$, and $\mathrm{CalR}+$ neurons in the cortical plate after injectable DXM given intraperitoneally $\left(0.1-1 \mathrm{mg} \cdot \mathrm{kg}^{-1}\right.$. $\left.12 \mathrm{~h}^{-1}\right)$ compared with PBS-treated pups $\left(0 \mathrm{mg} \cdot \mathrm{kg}^{-1} \cdot 12 \mathrm{~h}^{-1}\right.$ injectable DXM). Cell counts were made in a square-grid reticule of $0.25 \mathrm{~mm}^{2}$ for $\mathrm{CaBP}$ and CalR markers and of $0.065 \mathrm{~mm}^{2}$ for GABA marker.

branching, all of which may be altered by DXM in the postnatal period. As development proceeds, the chloride gradient becomes reversed compared with that in neonates, and excitation mediated by $\mathrm{GABA}_{\mathrm{A}}$ receptors is gradually replaced by inhibition (34-36). In the rat, this developmental switch occurs at approximately postnatal days 4-10, leading to transient expression of GABAergic markers in the cortical neurons; it is interesting that neurosteroid modulation of $\mathrm{GABA}_{\mathrm{A}}$ receptors in the developing rat brain cortex has been shown, manifesting as a 3- to 6-fold increase in receptor affinity on P5, at a period overlapping the developmental stages at treatment in our mouse model (37). Injectable DXM may interact with this switch, thereby leading to extended expression of GABAergic markers in a given neuronal subpopulation, which remains to be defined. Finally, GABA is synthesized in neurons by the rate-limiting enzyme glutamic acid decarboxylase (GAD), which exists as two isoforms, GAD65 and GAD67. It is 

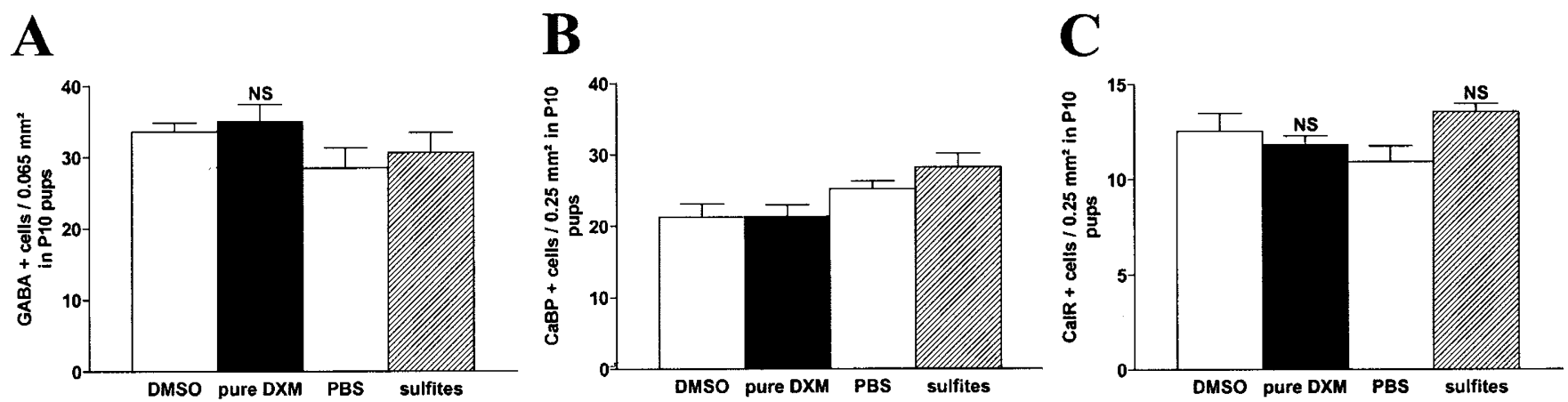

Figure 8. Pure DXM or sulfites alone did not increase GABAergic neurons in the cortical plate. Quantitative analysis of the numbers of GABA + neurons $(A)$, $\mathrm{CaBP}+$ neurons $(B)$, and CalR + neurons $(C)$ on $\mathrm{P} 10$ in the cingular cortex $(A)$ and the parietal cortex $(B$ and $C)$, respectively, in pups that were treated with pure DXM $(n=9)$ or sulfites $(n=5)$, compared with appropriate controls (DMSO and PBS, respectively). Comparisons were performed using one-way ANOVA with Dunnett comparison posttest.

interesting that alterations in gene transcription levels for both of these enzymes have been found in the hippocampus after perinatal DXM treatment (38).

The developmental imbalance between GABAergic neurons and other neuronal subpopulations invites questions about the cellular mechanism underlying the toxic effect of injectable DXM. We suggest two mechanisms, which might act alone or in combination: 1 ) increased cell death involving nonGABAergic neuronal subpopulation(s), as shown by cleaved caspase 3 immunocytochemistry, in keeping with previously described transferase-mediated dUTP nick-end labeling findings (15), and 2) increased survival of GABAergic neurons, as suggested by the increased density of GABA-IR, CaBP-IR, and CalR-IR neurons observed in the cortical plate.

Taken together, our data suggest that apoptotic neuronal loss in the cortical plate occurred after injectable DXM treatment and involved nonGABAergic neurons. We hypothesize that projection neurons might be more vulnerable to injectable DXM than other neuronal populations at the developmental stages investigated in our model. Moreover, the normal postnatal development of the GABA phenotype in the cerebral cortex includes a transient increase in the number of neurons expressing GABA on P5 followed by a decrease on P10 (39). This normally transient expression may become sustained under the influence of injectable DXM, resulting in an increased proportion of GABA-expressing cells compared with the normal cerebral cortex. The exact role of GABAergic neurons during development and the relationship with subsequent neurologic disorders is not yet clear. Further studies are needed to elucidate the role for these cells in the neuronal plasticity that occurs after brain damage.

Another crucial question is whether the DXM molecule itself was responsible for the findings in our model. We previously reported that injectable DXM and injectable betamethasone differed in their ability to protect against white matter damage in very premature infants who are treated prenatally (40). Injectable DXM preparations usually contain sulfites, whereas injectable betamethasone does not. Sulfites have neurotoxic and excitotoxic-like properties in vitro, which are enhanced by peroxynitrite generated in response to hypoxia-ischemia or inflammation. In a recent study, we demonstrated that the combination of DXM molecule and sulfites had
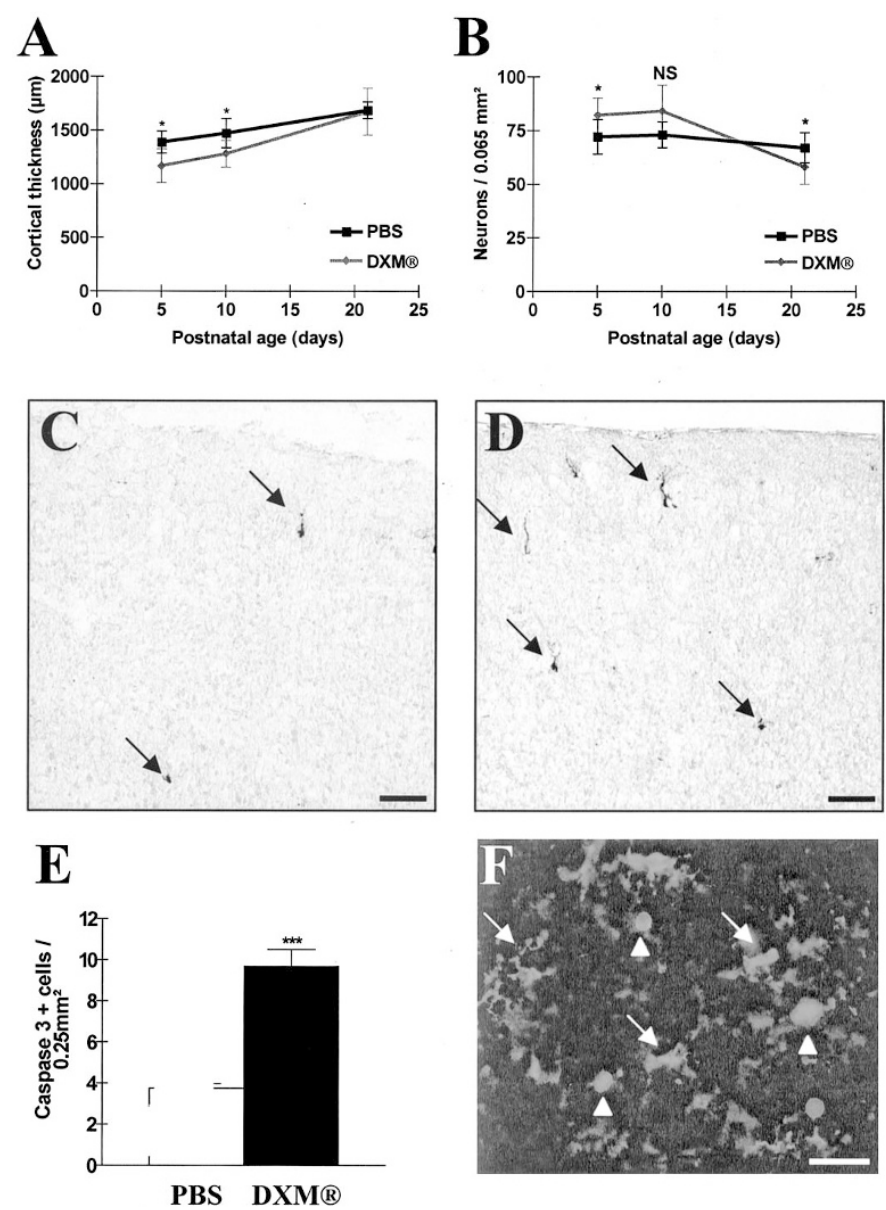

Figure 9. Injectable DXM increased neuronal cell death in the cortical plate. $(A$ and $B)$ Measurements of cortical thickness $(A)$ and neuronal density $(B)$ in the cortical plate (parietal area PAR1) in pups that were given PBS (control group) or injectable DXM (* $p<0.05$; NS, not significant, two-way ANOVA with the Bonferroni multiple comparisons posttest). ( $C$ and $D$ ) Representative coronal sections from injectable DXM-treated pups or controls (PBS) on P5. Immunolabeling for cleaved caspase 3 (the arrows indicate immunoreactive neurons). Bar $=40 \mu \mathrm{m}$. $(E)$ Quantitative analysis of the number of cleaved caspase 3 dying neurons in the parietal cortex after injectable DXM or PBS given intraperitoneally on P5 (***p $<0.001, t$ test). $(F)$ Double immunolabeling of coronal sections using mouse anti-CaBP and rabbit anti-cleaved caspase 3 antibodies in injectable DXM-treated pups on P5. The arrows indicate $\mathrm{CaBP}+$ interneuron, and the arrowheads indicate dying neurons. Bar $=40 \mu \mathrm{m}$. 
toxic effects on cultured neurons, whereas the dexamethasone molecule itself did not (15). A mixture that contained most of the compounds of injectable DXM preservatives (creatinine, sodium citrate, and parahydroxybenzoate, in addition to sodium metabisulfite) induced similar toxicity on neuronal cultures compared with sulfites alone, suggesting that sulfites per $s e$ were likely responsible for the deleterious effects observed (15). The findings reported here further support a key role for sulfites in neuronal survival or maturation, acting not alone but rather in combination with another metabolic, pharmacologic, or molecular event triggered by glucocorticoids. In addition, our data are strongly against the hypothesis of differences in pharmacokinetic properties between pure DXM and injectable DXM, the two preparations compared in this study. The mechanism of this noxious interaction between DXM and sulfites remains unknown.

\section{CONCLUSION}

In conclusion, the present study showed specific alterations in neuronal differentiation of the GABAergic system and interneurons in the cortical plate of mouse pups that were given postnatal injectable DXM. As the complex function of the neocortical circuitry depends on GABAergic local circuit neurons, this may account in part for the adverse neurodevelopmental effects of postnatal injectable DXM therapy in premature infants. Finally, our findings indicate a need for great caution when using sulfite-containing drug preparations during the perinatal period.

Acknowledgments. We are grateful to Leslie Schwendimmann for excellent technical assistance and to Dr. Annette Vigny for generously donating the tyrosine hydroxylase antibodies. We warmly thank Dr. Guy Aymard for help and expertise in measuring dexamethasone plasma concentrations.

\section{REFERENCES}

1. Slattery MM, Morrisson JJ 2002 Preterm delivery. Lancet 360:1489-1497

2. Mammel MC, Green TP, Johnson DE, Thompson TR 1983 Controlled trial of dexamethasone therapy in infants with bronchopulmonary dysplasia. Lancet 1:13561358

3. Avery GB, Fletcher AB, Kaplan M, Brudno DS 1985 Controlled trial of dexamethasone in respirator-dependent infants with bronchopulmonary dysplasia. Pediatrics 75:106-111

4. Bhuta T, Ohlsson A 1998 Systematic review and meta-analysis of early postnatal dexamethasone for prevention of chronic lung disease. Arch Dis Child Fetal Neonatal Ed 79:F26-F33

5. Halliday HL 1999 Clinical trials of postnatal corticosteroids: inhaled and systemic. Biol Neonate 76:29-40

6. Yeh TF, Lin YJ, Huang CC, Chen YJ, Lin CH, Lin HC, Hsieh WS, Lien YJ 1998 Early dexamethasone therapy in preterm infants: a follow-up study. Pediatrics 101:E7

7. Shinwell ES, Karplus M, Reich D, Weintraub Z, Blazer S, Bader D, Yurman S, Dolfin T, Kogan A, Dollberg S, Arbel E, Goldberg M, Gur I, Naor N, Sirota L, Mogilner S, Zaritsky A, Barak M, Gottfried E 2000 Early postnatal dexamethasone treatment and increased incidence of cerebral palsy. Arch Dis Child Fetal Neonatal Ed 83:F177F181

8. O'Shea TM, Kothadia JM, Klinepeter KL, Goldstein DJ, Jackson BG, Weaver RG 3rd, Dillard RG 1999 Randomized placebo-controlled trial of a 42-day tapering course of dexamethasone to reduce the duration of ventilator dependency in very low birth weight infants: outcome of study participants at 1-year adjusted age. Pediatrics 104:15-21

9. Baud O 2001 Is perinatal dexamethasone treatment safe in preterm infants? Dev Med Child Neurol Suppl 86:23-25

10. Barrington KJ 2001 The adverse neuro-developmental effects of postnatal steroids in the preterm infant: a systematic review of RCTs. BMC Pediatr 1:1
11. Halliday HL 2002 Early postnatal dexamethasone and cerebral palsy. Pediatrics 109:1168-1169

12. Murphy BP, Inder TE, Huppi PS, Warfield S, Zientara GP, Kikinis R, Jolesz FA, Volpe JJ 2001 Impaired cerebral cortical gray matter growth after treatment with dexamethasone for neonatal chronic lung disease. Pediatrics 107:217-221

13. Modi N, Lewis H, Al-Naqeeb N, Ajayi-Obe M, Dore CJ, Rutherford M 2001 The effects of repeated antenatal glucocorticoid therapy on the developing brain. Pediatr Res 50:581-585

14. Bos AF, Martijn A, van Asperen RM, Hadders-Algra M, Okken A, Prechtl HF 1998 Qualitative assessment of general movements in high-risk preterm infants with chronic lung disease requiring dexamethasone therapy. J Pediatr 132:300-306

15. Baud O, Laudenbach V, Evrard P, Gressens P 2001 Neurotoxic effects of fluorinated glucocorticoid preparations on the developing mouse brain: role of preservatives. Pediatr Res 50:706-711

16. Flagel SB, Vazquez DM, Watson SJ Jr, Neal CR Jr 2002 Effects of tapering neonatal dexamethasone on rat growth, neurodevelopment, and stress response. Am J Physiol 282:R55-R63

17. Brabham T, Phelka A, Zimmer C, Nash A, Lopez JF, Vazquez DM 2000 Effects of prenatal dexamethasone on spatial learning and response to stress is influenced by maternal factors. Am J Physiol 279:R1899-R1909

18. Felszeghy K, Gaspar E, Nyakas C 1996 Long-term selective down-regulation of brain glucocorticoid receptors after neonatal dexamethasone treatment in rats. J Neuroendocrinol 8:493-499

19. Ferguson SA, Holson RR 1999 Neonatal dexamethasone on day 7 causes mild hyperactivity and cerebellar stunting. Neurotoxicol Teratol 21:71-76

20. Ferguson SA, Paule MG, Holson RR 2001 Neonatal dexamethasone on day 7 in rats causes behavioral alterations reflective of hippocampal, but not cerebellar, deficits. Neurotoxicol Teratol 23:57-69

21. Beaulieu C 1993 Numerical data on neocortical neurons in adult rat, with special reference to the GABA population. Brain Res 609:284-292

22. Ungerstedt U 1971 Stereotaxic mapping of the monoamine pathways in the rat. Acta Physiol Scand Suppl 367:1-48

23. Hökfelt T, Martensson R, Björklund A, Kleinau S, Golstein M 1984 Distributional maps of tyrosine hydroxylase-immunoreactive neurons in the rat brain. In: Björklund A, Hökfelt T (eds) Handbook of Chemical Neuroanatomy, Vol 2: Classical Transmitters in the CNS, Part 1. Elsevier Science Publishers, Amsterdam, pp 277-379

24. Berger B, Gaspar P, Verney C 1991 Dopaminergic innervation of the cerebral cortex: unexpected differences between rodents and primates. Trends Neurosci 14:21-27

25. Dobbing J 1974 The later development of the brain and its vulnerability. In: Davis JA, Dobbing J (eds) Scientific Foundation of Paediatrics. Heinemann, London, pp 565577

26. Zilles KJ 1985 The Cerebral Cortex of the Rat. A Stereotactic Atlas. Berlin, Springer-Verlag

27. Paxinos G, Watson C 1998 The Rat Brain in Stereotaxic Coordinates, 4th Ed. Academic Press, San Diego

28. Rogers JH 1992 Immunocytochemical markers in rat cortex: co-localization of calretinin and calbindin-D28k with neuropeptides and GABA. Brain Res 587:147157

29. Laurie DJ, Bartke I, Shoepfer R, Naujoks K, Seeburg PH 1997 Regional, developmental and interspecies expression of the four NMDAR2 subunits, examined using monoclonal antibodies. Brain Res Mol Brain Res 51:23-32

30. Tobimatsu T, Fujisawa H 1989 Tissue-specific expression of four types of rat calmodulin-dependent protein kinase II mRNAs. J Biol Chem 264:17907-17912

31. Dobbing J 1981 The later development of the brain and its vulnerability. In: Davis JA (ed) Scientific Foundation of Paediatrics. Heinemann, London, pp 744-759

32. Hagberg H, Bona E, Gilland E, Puka-Sundvall M 1997 Hypoxia-ischemia model in the 7 day old rat: possibilities and shortcomings. Acta Paediatr Suppl 422:85-88

33. Whitelaw A, Thoresen M 2000 Antenatal steroids and the developing brain. Arch Dis Child Fetal Ed 83:F154-F157

34. Owens DF, Boyce LH, Davis MB, Kriegstein AR 1996 Excitatory GABA responses in embryonic and neonatal cortical slices demonstrated by gramicidin perforatedpatch recordings and calcium imaging. J Neurosci 16:6414-6423

35. Rohrbough J, Spitzer NC 1996 Regulation of intracellular $\mathrm{Cl}$ - levels by $\mathrm{Na}+$ dependent $\mathrm{Cl}$ - cotransport distinguishes depolarizing from hyperpolarizing GABAA receptor-mediated responses in spinal neurons. J Neurosci 16:82-91

36. Plotkin MD, Snyder EY, Hebert SC, Delpire E 1997 Expression of the Na-K-2C cotransporter is developmentally regulated in postnatal rat brains: a possible mechanism underlying GABA excitatory role in immature brain. J Neurobiol 33:781-795

37. Borodinsky LN, Pesce G, Pomata P, Fiszman ML 1997 Neurosteroid modulation of $\mathrm{GABA}_{\mathrm{A}}$ receptors in the developing rat brain cortex. Neurochem Int 31:313-317

38. Stone DJ, Walsh JP, Sebro R, Stevens R, Pantazopolous H, Benes FM 2001 Effects of pre- and postnatal corticosterone exposure on the rat hippocampal GABA system. Hippocampus 11:492-507

39. Micheva KD, Beaulieu C 1995 Postnatal development of GABA neurons in the rat somatosensory barrel cortex: a quantitative study. Eur J Neurosci 7:419-430

40. Baud O, Foix-L'Helias L, Kaminski M, Audibert F, Jarreau PH, Papiernik E, Huon C, Lepercq J, Dehan M, Lacaze-Masmonteil T 1999 Antenatal glucocorticoid treatment and cystic periventricular leukomalacia in very premature infants. N Engl J Med 341:1190-1196

41. Vigny A, Henry JP 1981 Bovine adrenal tyrosine hydroxylase: comparative study of native and proteolysed enzyme and their interaction with anions. J Neurochem 36:483-489 